\title{
Non-invasive flow path characterization in a mining-impacted wetland
}

\author{
James Bethune $^{a, *}$, Jackie Randella, Robert L. Runkel ${ }^{\mathrm{b}}$, Kamini Singha ${ }^{\mathrm{a}}$ \\ ${ }^{a}$ Hydrologic Science and Engineering Program, Colorado School of Mines, 1500 Illinois St. \\ Golden, CO 80401 \\ ${ }^{b}$ U.S. Geological Survey, 3215 Marine Street, Suite E-127, Boulder, CO 80303
}

\begin{abstract}
Time-lapse electrical resistivity (ER) was used to capture the dilution of a seasonal pulse of acid mine drainage (AMD) contamination in the subsurface of a wetland downgradient of the abandoned Pennsylvania Mine workings in central Colorado. Data were collected monthly from mid-July to late October of 2013, with an additional dataset collected in June of 2014. Inversion of the ER data shows the development through time of multiple resistive anomalies in the subsurface, which corroborating data suggest are driven by changes in total dissolved solids (TDS) localized in preferential flow pathways. Sensitivity analyses on a synthetic model of the site suggest that the anomalies would need to be at least several meters in diameter to be adequately resolved by the inversions. The existence of preferential flow paths would have a critical impact on the extent of attenuation mechanisms at the site, and their further characterization could be used to parameterize reactive transport models in developing quantitative predictions of remediation strategies.

Keywords: Acid mine drainage, electrical resistivity, wetland
\end{abstract}

\section{Introduction}

Weathering of sulfide deposits creates a serious environmental water quality issue by generating acidic conditions and mobilizing heavy metals (see Da Rosa et al., 1997; Nordstrom, 2011b, for reviews). Although acid rock drainage forms naturally as a byproduct of sulfide oxidation, mining operations can increase the

${ }^{*}$ Corresponding author: james.c.bethune@gmail.com Preprint submitted to Journal of Contaminant Hydrology

September 15, 2015 
weathering rate by up to three orders of magnitude by increasing the reactive mineral surface area (Alpers et al., 2007). The effects of acid mine drainage (AMD) can persist for decades or even centuries after mining operations have ceased through continued oxidation and dissolution of acid-releasing minerals (Younger, 1997).

Effective remediation of AMD requires detailed knowledge of contaminant transport through the subsurface, where longer retention times may allow for extended contact with attenuating or neutralizing agents (Zhu et al., 2002). Heterogeneity and preferential flow path development in AMD settings has been shown to decrease the efficiency of contaminant attenuation (Malmström et al., 2008), likely because preferential flow paths reduce the residence time of solutes in the subsurface and contact with attenuating agents (Brusseau, 1994). Preferential flow paths would be expected in mining-disturbed settings because deposition of mining waste piles typically results in graded bedding with a wide range of hydraulic conductivities (Morin \& Hutt, 1994; Smith, 1995). Unfortunately, the subsurface is rarely mapped to a sufficient extent to identify and characterize flow paths, especially at historical mine sites, where efforts generally contend with a lack of site data and highly disturbed aquifer material (e.g., Oram et al., 2010; Nordstrom, 2011a). Many AMD remediation projects expend considerable effort quantifying flow and transport parameters through tracer injections (Benner et al., 2002), hydrograph separation (Smith, 1995), flow balance calculations (Gélinas et al., 1994), and aquifer permeability tests, or are otherwise forced to make simplifying assumptions regarding subsurface homogeneity.

The high pore fluid conductivity of AMD has been demonstrated to be a useful tracer for mapping mining contamination (Gray, 1996), and an excellent target for electrical geophysical methods (Merkel, 1972). Electrical resistivity (ER) is a geophysical technique that measures the bulk electrical conductivity of the subsurface by both establishing a potential gradient between a pair of electrodes and measuring the potential drop across one or more pairs of other electrodes (Binley \& Kemna, 2005). The procedure is repeated for many differ- 
1 ent electrode locations to develop a spatially distributed dataset of subsurface conductivity (See Loke et al., 2013, for a recent review). Where a consistent relationship exists between pore fluid and bulk conductivities, ER can be used to delineate the extent and magnitude of a contaminant plume (e.g., Spindler \& Olyphant, 2004).

Time-lapse ER can circumvent the reliance on a consistent relationship between pore fluid and bulk conductivities by monitoring changes in subsurface electrical properties and attributing them to changes in pore fluid conductivity. Many time-lapse ER studies inject a conductive tracer to facilitate flow path imaging (e.g., Kemna et al., 2002; Ward et al., 2010; Pollock \& Cirpka, 2012); however, the 'first-flush' behavior demonstrated by many mine sites creates an ideal natural electrical signal. The largest contaminant loads emanating from mine sites are typically coincident with large storms following prolonged dry conditions (Miller \& Miller, 2007; Nordstrom, 2009). This results in a seasonal pulse of AMD that can be used in place of a traditional tracer study, allowing for the exploration of a greater support volume and the characterization of natural flow fields (Tiedeman \& Hsieh, 2004).

The goals of this paper are twofold: (1) to demonstrate the use of time-lapse ER to map AMD flow paths with application to characterizing contaminant transport, and (2) to investigate the sensitivity of ER to different conductivity anomaly sizes and magnitudes. Inverting ER measurements using a standard L2-norm to calculate model resistance values necessarily involves smoothing, which may lead to some smaller features being difficult to resolve (Day-Lewis et al., 2005). An understanding of the capabilities of ER to resolve features of different sizes is crucial for quantitative analysis in AMD settings, where target anomaly sizes may not be easily constrained. ER has been previously used to characterize the extent of AMD contamination, but only using a single snapshot in time with application of rock physics relations (e.g., Oldenburg \& Li, 1994; Rucker et al., 2009). Here, time-lapse ER is used to image the dilution of the natural AMD conductivity pulse to characterize subsurface flow. 


\section{Field site description}

This research was conducted in a wetland between the historic Pennsylvania Mine and Peru Creek, a headwater stream to the Colorado River in central Colorado (Figure 1). The Peru Creek basin is bracketed on the north and east by the Continental Divide, and drains west into the Snake River. Because $80 \%$ of precipitation falls as snow, the hydrograph is dominated by a spring snowmelt pulse (Crouch et al., 2013).

The local geology includes part of a heavily mined Oligocene quartz monzonite porphyry of the Montezuma district. The Montezuma stock intruded Precambrian schist and gneiss, causing extensive fracturing and faulting and widely disseminating pyrite (Fey et al., 2001). The mineral assemblage includes abundant sulfides, in particular pyrite $\left(\mathrm{FeS}_{2}\right)$, sphalerite $([\mathrm{Zn}, \mathrm{Fe}] \mathrm{S})$, and galena (PbS) (Lovering, 1935). The Snake River contains ecologically toxic concentrations of zinc, cadmium, and copper as a result of natural and anthropogenically induced pyrite weathering (Wood et al., 2005). A study of the nearby Handcart Gulch, an unmined drainage near the edge of the Montezuma district, found deposits of ferricrete (iron oxide) coating the streambed (Verplanck et al., 2009), indicating that background metal concentrations are high even in unmined drainages in the area, likely due to natural weathering of sulfide minerals. Fracture flow associated with the Colorado Mineral Belt has been suggested to enhance the rate of pyrite weathering in both mining impacted and unimpacted areas, though the precise nature and cause of the fractures is uncertain (Wood et al., 2005; Caine \& Tomusiak, 2003).

Regionally, sulfate concentrations, which are a common proxy of mining contamination, are highest in areas with extensive mining and hydrothermal alteration (Fey et al., 2001). There are many abandoned mines scattered throughout the region, but water and sediment chemistry analyses of the Snake River reveal that one of the largest contributors of metals is the Pennsylvania Mine reach of Peru Creek (Todd et al., 2005).

The Pennsylvania Mine was one of the largest mines in the region during 


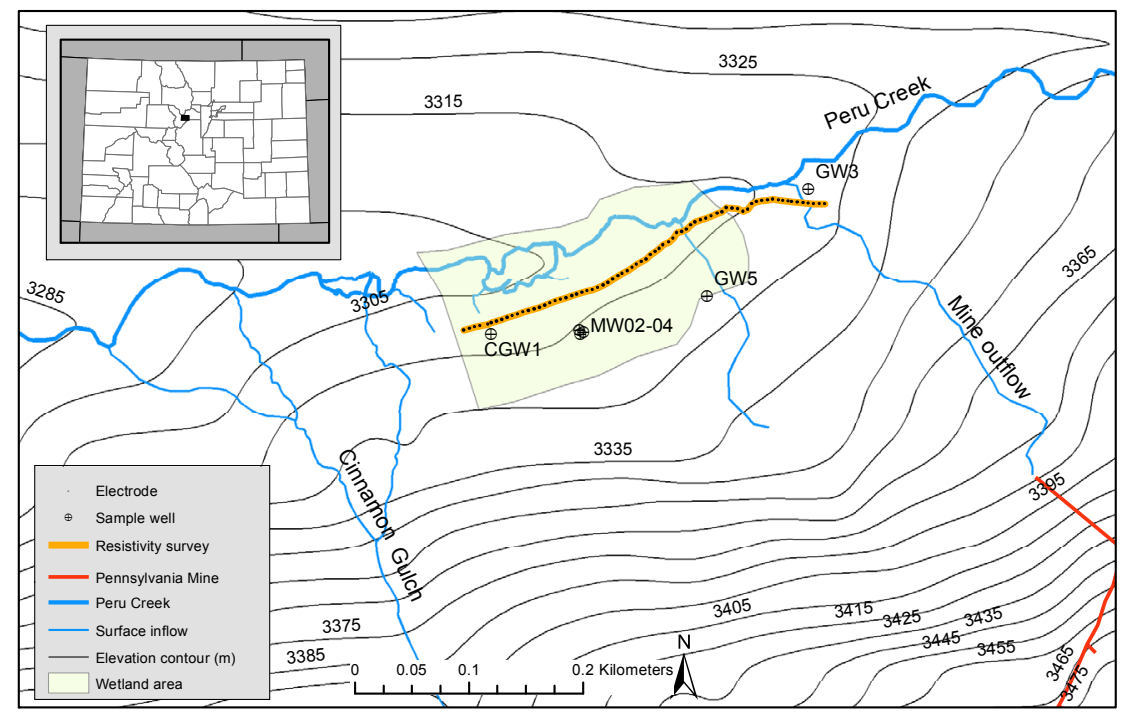

Figure 1: Map of study region with Peru Creek, ER array, and borehole sample locations.

1 its operation from 1885 to 1953 (Bird, 2003). The extensive underground mine workings were historically accessed via six adits, two of which remain at least partially open today (Lovering, 1935; Wood et al., 2005). A surface flow exits the lower adit and discharges into Peru Creek approximately $100 \mathrm{~m}$ upgradient from the wetland (Figure 1).

Because of its significant impact on local water sources, the surface water chemistry of Peru Creek has been studied extensively (McKnight \& Bencala, 1990; Sullivan \& Drever, 2001; Fey et al., 2001; Runkel et al., 2013). There 9 is a large seasonality to both surface flow and contaminant concentration and loading in Peru Creek (Sullivan \& Drever, 2001). The peak flow occurs in late 11 May to early June and is typically 5-10 times as great as low flow during early 12 spring (Todd et al., 2005; Sullivan \& Drever, 2001). Metals concentrations in 13 the mine outflow are highest during the high spring flows, consistent with the 14 first-flush behavior identified at other mine sites, although the spring concentra15 tion peaks are typically broader than those observed at some other mine sites 
1 (Chapin \& Todd, 2012). In September of 2009, synoptic sampling along the 2 Pennsylvania Mine reach of Peru Creek identified a diffuse contaminant source emanating from the wetland area, where Peru Creek discharge was found to increase from $60 \mathrm{~L} / \mathrm{s}$ to $80 \mathrm{~L} / \mathrm{s}$ in the wetland area, and sampled inflows did not close the discharge or contaminant load budget (Runkel et al., 2013). Inflows emanating from the wetland had higher metal concentrations than Peru Creek indicating that the wetland is mining impacted (Runkel et al., 2013). In-stream concentrations of specific metals were variable over the wetland reach: moving downstream, concentrations of $\mathrm{Cu}, \mathrm{Zn}$, and $\mathrm{Cd}$ increased, while concentrations of Fe and $\mathrm{Pb}$ decreased (Runkel et al., 2013). Chemical mixing and end-member analyses indicated that the wetland samples are a mixture of Pennsylvania Mine water and Cinnamon Gulch water, supporting the hypothesis that water is moving from the mine workings into the wetland (Runkel et al., 2013). Chemical resemblance between the mine and wetland waters could also be a result of contamination produced by tailing piles in the wetland (Runkel et al., 2013).

There are several pathways through which contamination could be reaching the wetland area. The wetland has large deposits of potentially AMD-generating waste rock. Using an average precipitation total of $91 \mathrm{~cm} /$ year, and estimating the total waste rock area as $4,600 \mathrm{~m}^{2}$, the Colorado Geological Society estimated that an annual average of $0.5 \mathrm{~m}^{3} / \mathrm{hr}$ of flow could be passing through waste rock and into groundwater each year (Wood et al., 2005). Water budget calculations from Cinnamon Gulch (Figure 1) show that the vast majority (>95\%) of discharge to Peru Creek is from groundwater inflow (Wood et al., 2005). Furthermore, a tracer injected directly into the mine was recovered in boreholes in the wetland about 100 days after injection, indicating there is a hydrological connection with the mine (Mark Rudolph, personal communication). Chemical analyses of groundwater sampled downgradient from the mine suggest that the mine outflow is infiltrating into the wetland area (Rudolph, 2010). TDS levels are highest in the deeper wells, indicating that the wetland connection with the mine workings or other tailings piles is through the deeper fractured granite bedrock (Rudolph, 2010). 
Flow through the wetland was previously studied to evaluate the site's capacity to naturally attenuate redirected mine effluent (Emerick et al., 1988). Boreholes near the area of interest include MW02, MW03, MW04, GW5, CGW1, and GW3, which were installed to various depths and screened intervals across the site. MW02 is screened into deeper granite bedrock (from 14-16.8 m below ground surface, or bgs); MW03 is screened into a sandy gravel layer (5.5-8.5 m bgs); GW5 is screened into peat and intermixed tailings (1.5-3 m bgs); MW04 and CGW1 are screened into clay and peat (1.5-3 m bgs and 0.3-1.4 $\mathrm{m}$ bgs, respectively); and GW3 is screened into Peru Creek alluvium (1.5-4.6 m bgs). Interpolation of the borehole logs suggests that the upper layer of clay and silt in the wetland is bowl-shaped, roughly $5 \mathrm{~m}$ thick in the middle and tapering out toward the edges (Emerick et al., 1988). The hydraulic conductivity of this uppermost layer was found to be highly variable, with recovery rates from bailing tests of the boreholes spanning orders of magnitude (Emerick et al., 1988). The highly variable recovery rates were attributed to anomalous 5-8 cm thick layers of fine-grained clayey sand encountered in multiple boreholes (Emerick et al., 1988).

\section{Methods}

An array of 72 electrodes with 5-meter spacing was installed east to west, through the wetland area and across the mine outlet, running roughly parallel to the creek (Figure 1). Resistance data were collected on a 645 dipole-dipole quadripole sequence, which was collected in 3 replicates each field session to better estimate measurement error. Each stored quadripole measurement represents the average of a stack of 3-6 separate measurements, resulting in a total of 9-18 measurements collected per quadripole per field session. The dipole-dipole geometry allows for up to 10 measurements to be collected simultaneously with a 10-channel Syscal Pro resistivity meter (IRIS Instruments, Orleans, France), resulting in a total collection time of approximately 15 minutes per sequence. Initial conductivity data were collected on July 12th, 2013. Subsequent time- 
steps were collected at approximately 2-week intervals, until the road was inaccessible in late October 2013. An additional dataset was collected in June of 2014.

Electrodes were constructed from $75 \mathrm{~cm}$ X $1.27 \mathrm{~cm}$ schedule-40 PVC, wrapped with $8 \mathrm{~cm}$ of conductive foil tape approximately $10 \mathrm{~cm}$ from one end. Each electrode was installed to $20 \mathrm{~cm}$ bgs and connected to the ER meter using 18-gauge tinned copper wire and prebuilt cables. Electrodes were left in place throughout the field campaign, including over the winter season. Contact resistance was checked at each electrode before each survey, and was consistently less than 1 kohm in the wetland, indicating excellent electrical connection with the ground. Electrodes on the east side of the array had higher contact resistance, typically between 10-20 kohm, and needed to be manually removed and replaced between each survey because of their proximity to a road. Elevations of each electrode were recorded using a Trimble XT6000 GPS unit, and post-corrected with GPS Pathfinder Office 2, resulting in sub-decimeter accuracy in the horizontal direction, and 10-20 $\mathrm{cm}$ accuracy in the vertical direction.

17 Ancillary data that were collected to facilitate interpretation of the ER measurements include: pore fluid conductivity, temperature, and water levels in 6 pre-existing wells (identified as MW02, MW03, MW04, CGW1, GW3, and GW5

20 in Figure 1) using a Solinst water level probe. In each borehole, temperature 21 and fluid conductivity data were collected at water level, as well as the top, 22 middle, and bottom of the screened interval, synchronous to, or immediately following, ER measurements. Pressure transducers were left in four monitoring wells (MW02, MW03, MW03, CGW1) over winter and spring to monitor water 25 level, temperature, and pore fluid conductivity. Peru Creek flow was gaged near flow was monitored continuously with two pressure transducers until Nov 4th, 2013. 


\section{3.1. Inversion}

2 ER measurements were inverted using R2 (v2.7, Generalized 2-D Inversion

3 of Resistivity Data, (described in Binley \& Kemna, 2005)). Inversions are inher-

4 ently non-unique and ill-posed because model unknowns typically greatly out-

5 number measurements (LaBrecque et al., 1996), and hence require additional

6 model constraints. To satisfy that requirement, R2 uses regularized optimiza-

7 tion, which seeks to minimize both data misfit and model roughness (Tikhonov

$8 \quad \&$ Arsenin, 1977). The objective function, $\psi()$, takes the form:

$$
\psi(m)=\left(W_{d}(m)[d-f(m)]\right)^{2}+\alpha\left(W_{m}\left[m-m_{r e f}\right]\right)^{2}
$$

9 where

$$
\begin{aligned}
m & \text { model vector } \\
d & \text { measured resistance data, log transformed } \\
W_{d} & \text { data weighting matrix } \\
f(m) & \text { forward solution operating on the model } \\
W_{m} & \text { model weighting matrix that typically evaluates } \\
& \text { model roughness } \\
\alpha & \text { weight that controls the relative importance of the } \\
& \text { two terms on the right side of the equation } \\
m_{r e f} & \text { starting model guess }
\end{aligned}
$$

10 Conceptually, the $W_{m}$ term of Equation 1 measures model roughness, the $W_{d}$

11 term measures misfit, and the $\alpha$ value controls their relative weights. Inversions

12 require an initial guess or model starting value, $m_{r e f}$. In time-lapse $\mathrm{ER}, m_{r e f}$

13 refers to the inversion of the initial dataset.

14 A finite-element mesh was designed with $1 \mathrm{~m} \mathrm{x} 1 \mathrm{~m}$ elements to $20 \mathrm{~m}$ depth,

15 below which depth element size gradually increased, resulting in 10,152 total elements. Element sizes were slightly irregular, because nodes were placed at each electrode location in the model. 
Lewis et al., 2005). The resolution matrix, $\mathbf{R}$, is quantified as:

$$
\hat{m} \approx R m_{\text {true }}
$$

in which $\hat{m}$ is the model estimate, and $m_{\text {true }}$ is the true conductivity value of the measured domain. The diagonal of $\mathbf{R}$ quantifies the degree to which the value of a given pixel in the inversion is informed by the data corresponding to to that pixel, as opposed to the smoothing influence of the regularization term.

${ }_{11}$ To limit interpretation of results dominated by smoothing, inversion results 12 corresponding to values less than $10^{-2.5}$ in the diagonal of their resolution matrix However, the degree of smoothing varies over the model space, resulting in an inversion having less resolving power in some regions than in others. Resolution matrices quantify the degree of smoothing associated with a given element (Daywere filtered from the analysis.

\subsection{Evaluating Error}

Appropriately defining measurement and model error is vital to achieving proper inversion fit. Error estimates that are too low result in a noisy inversion model with artifacts, while error estimates that are too high result in an overly smooth model with low resolving power (LaBrecque et al., 1996). The data weighting term in Equation 1, $\mathrm{W}_{d}$, is typically of the form $\operatorname{diag}\left(1 / \epsilon_{1}, \ldots, 1 / \epsilon_{n}\right)$, in which $\epsilon_{i}$ is the percent standard deviation associated with a stack of quadripole resistance measurements.

R2 allows for measurement error to be calculated based on a generalized error model, but this method not did adequately capture the measurement variability between between data stacks, which was often much higher than variability within individual stacks. To account for the inter-stack variability, total measurement error for each quadripole was calculated as the global percent standard deviation from the three replicate stacks. Final measurement error was then either taken to be the total measurement error, or the reported

Because of the regularization term in Equation 1, the resulting tomograms smoothed depictions of the subsurface bulk electrical conductivity. 
1 precision of the Syscal Pro unit $(0.2 \%)$, whichever was greater. Throughout the study period, instrumentation error was generally adopted as measurement error for quadripoles in the wetland because of the consistency between the stack measurements.

Some quadripoles covering the far eastern part of the survey measured unreasonably large changes in resistance between time-steps, likely due to electrode placement issues in resistive ground and local construction activities. To make sure that these suspect quadripoles did not negatively affect the analysis, quadripoles measuring resistance values with a coefficient of variation greater than 1 over the survey duration were filtered out of the analysis.

Model error was assessed by comparing the apparent resistivities resulting from a forward solution on an homogeneous model with a flat surface boundary (Binley \& Kemna, 2005). The average model error was 0.5\%. Total error for each quadripole was taken to be the sum of measurement error and model error.

\section{Results}

\subsection{Conductivity}

The background bulk conductivity data (Figure 2) conform to the lithological 18 interpretations made from borehole drilling logs (Emerick et al., 1988; Rudolph, 19 2010). There is a bowl-shaped, high conductivity ( $>10 \mathrm{mS} / \mathrm{m}$, colors deep blue and cooler on Figure 2) unit in the wetland with a maximum thickness of about 4-5 $\mathrm{m}$ that tapers out toward the edges of the wetland area. The conductivity of this unit is typical of clays (Telford \& Sheriff, 1990), and its interval corresponds well with the wetland complex of interbedded clays and peat logged in boreholes MW02-04 and CGW1. This unit appears to pinch out somewhat near the middle of the structure. There is a less conductive unit extending from electrode 48, located at $\mathrm{x}=240 \mathrm{~m}$ in Figure 2, at the surface down and to the west that corresponds to the layer of sand and gravel observed in MW02, and the tailings observed in GW5. Below the sand layer, conductivity decreases to less than 2 $\mathrm{mS} / \mathrm{m}$ (colors bright yellow and warmer), typical of the granite bedrock with 


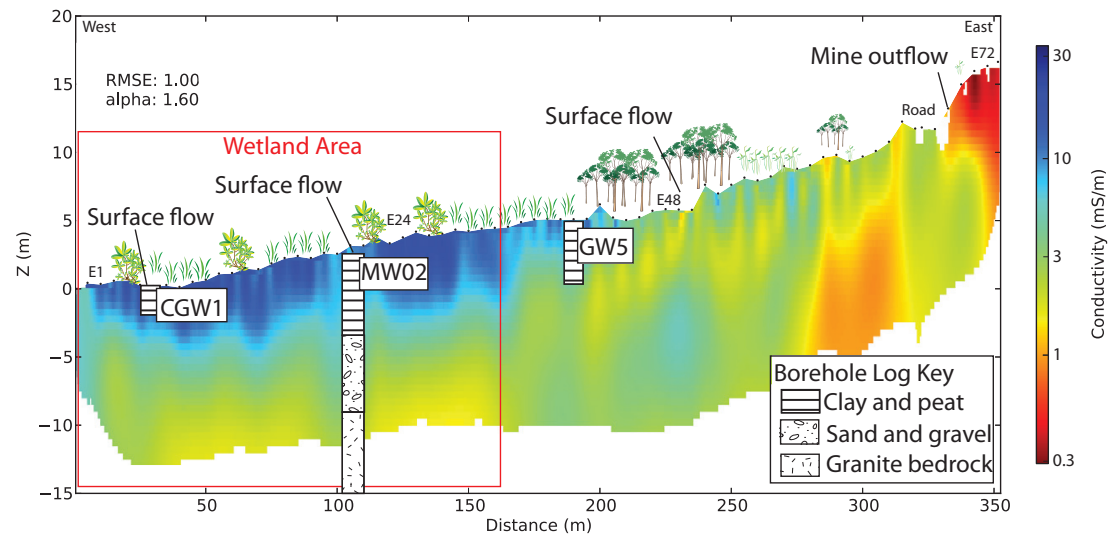

Figure 2: Inversion of ER data collected on July 12th, 2013 showing the depth profile conductivity. Electrodes (E1-E72), model fitting parameter results, borehole logs, and the general character of vegetation are shown.

high fluid conductivity observed in the bottom of MW02, though this depth 2 is approaching the resolution limit of this study. The low conductivity unit 3 approaches the surface near electrode 48 , where there is a small surface flow, 4 consistent with the interpretation of a granite bedrock contact.

Resolution on the east side of the profile was impacted by local construction activities and the complication of reinstalling electrodes with each survey (Figure 3). Consequently, the time-lapse data from the east side of the pro8 file are difficult to interpret, and so only the results from the wetland will be 9 shown here. In general, the high conductivities observed in the wetland area 10 are absent on the east side of the profile, indicating a lack of clay deposits. The 11 low conductivities under electrodes $68-72$, located at $\mathrm{x}=325 \mathrm{~m}$ to $350 \mathrm{~m}$, likely 12 correspond to dry granite bedrock.

Time-lapse ER data collected from July 2013 to June 2014 in the wetland 14 area show the development of two resistive anomalies at approximately $5 \mathrm{~m}$ 15 bgs, just under the interpreted boundary between the clay and peat layer and 16 the sandy layer (Figure 4), and the development of a laterally extensive resistive ${ }_{17}$ feature in the near-surface $(<3 \mathrm{~m})$ of the wetland. Both root-mean-square errors 


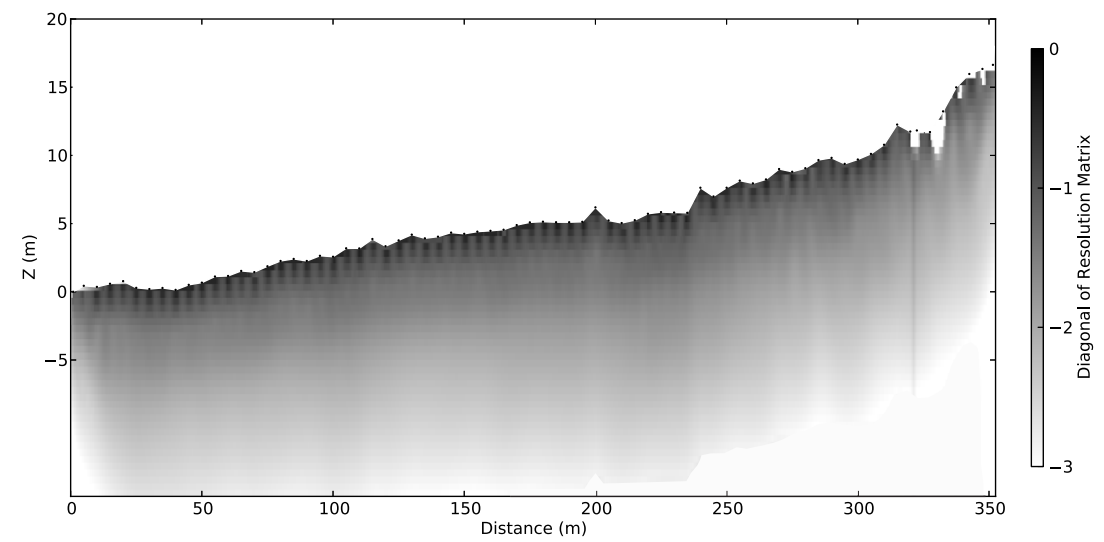

Figure 3: Resolution of inversion of data collected on July 12th, 2013. Note, because of smoothing issues, only data for $1 \mathrm{~m} \mathrm{x} 1 \mathrm{~m}$ pixels are shown.

between the modeled and measured data as well as the term controlling the relative weights between the model and data misfit were consistent for inversion results in the wetland throughout the study period, indicating that the degree of smoothing in the inversion results is fairly consistent through time, and therefore cannot explain the development of the temporal wetland anomalies. To confirm that the anomalies were not artifacts of data noise in the initial dataset, the resistance data were reanalyzed using the September inversion as the initial model condition, which resulted in slightly muted, but persistent, resistivity anomalies in the same locations, indicating that the anomalies represent real changes in field site conditions. Note that because bulk background conductivity decreases with depth at this site, absolute changes at depth produce a more pronounced relative change; as a result, the apparent surficial resistive anomalies 3 in the data represent smaller relative conductivity changes than the anomalies 14 observed at greater depths.

\subsection{Supporting Data}

Three parameters most likely explain the development of the resistive anoma-

17 lies at depth: water content, temperature, and pore fluid conductivity. Field 


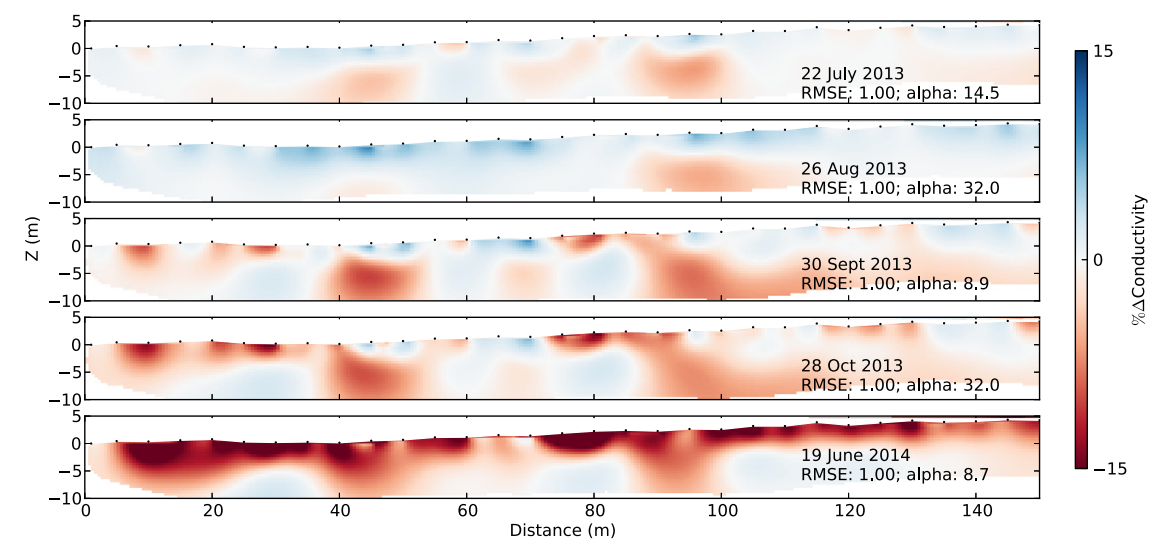

Figure 4: Time-lapse percent change in conductivity, relative to background inversion of July 12, 2013 data.

1

observations suggested and water levels in the boreholes confirmed that the wetland stayed saturated throughout the field campaign, as the static water level was typically within $0.5 \mathrm{~m}$ of the ground surface. Furthermore, contact resistance measured between adjacent pairs of electrodes in the wetland was consistent throughout the study period, indicating that there was minimal change in saturation in the wetland. As a result, saturation differences cannot explain the development of the resistive anomalies, particularly beyond a meter or so below ground surface.

Seasonally driven temperature decreases would be expected between July and October, particularly in the very shallow subsurface. Furthermore, localized enhanced communication of groundwater with surface water could produce imagable temperature anomalies in the deeper subsurface, in effect acting as a temperature tracer (Musgrave \& Binley, 2011). To explore the possibility of the anomalies being temperature based, the electrical conductivity response to changes in temperature was modeled (Schon, 2004):

$$
\sigma(T)=\sigma\left(T_{0}\right)\left[1+\beta\left(T-T_{0}\right)\right]
$$


1 where

$$
\begin{aligned}
\sigma & \text { conductivity }(\mathrm{mS} / \mathrm{m}) \\
T & \text { temperature }\left({ }^{\circ} \mathrm{C}\right) \\
T_{0} & \text { initial temperature }\left({ }^{\circ} \mathrm{C}\right) \\
\beta & \text { constant, equal to } 0.025\left({ }^{\circ} \mathrm{C}^{-1}\right) .
\end{aligned}
$$

2 Over the course of the field campaign, temperatures in the top $2 \mathrm{~m}$ bgs gener3 ally increased by about $2.5{ }^{\circ} \mathrm{C}$ by the end of September, before decreasing by 4 about $2.5{ }^{\circ} \mathrm{C}$ by the end of October. According to Equation 3, a temperature decrease of $2.5{ }^{\circ} \mathrm{C}$ would produce a $6.8 \%$ decrease in conductivity, which would not completely explain the resistive anomalies. However, the development of a localized layer of ice, which is much more resistive than water, at the site in October indicates that some areas had more pronounced cooling than others. A temperature decrease of $8{ }^{\circ} \mathrm{C}$ would produce a conductivity decrease of $25 \%$, which is entirely within the range of the observed data. It therefore likely that the resistive anomalies that developed on the surface were primarily temperature driven. However, water temperatures in the boreholes remained relatively constant $\left(+/-1{ }^{\circ} \mathrm{C}\right)$ at depths greater than $1.5 \mathrm{~m}$ bgs. At the outset of the study, the average temperature at depth was approximately $3.5^{\circ} \mathrm{C}$, indicating that a highly improbable phase change would need to occur to produce the resistive anomalies at depth. Therefore, it is unlikely that the resistivity anomalies at depth could be completely explained by temperature changes.

This leaves fluid conductivity change as the most likely explanation for the development of the wetland anomalies. Conductivity decreases could have occurred if preferential flow paths in the wetland allow for the flushing of high pore fluid salinity following the first-flush pulse. Because the contamination is typically produced during the dry season, additional flow through the system after the spring snowmelt pulse has flushed out the accumulated TDS would have lower TDS concentrations and produce a more resistive signal. 
There are multiple lines of evidence in the borehole data to suggest that such preferential flow paths exist in the wetland: (1) Initial TDS values were more variable and changes were more localized than they were for temperature. (2) There was little consistency between boreholes screened into the same aquifer; for example, CGW1 had TDS concentrations that were nearly an order of magnitude higher than MW02, even though they are $100 \mathrm{~m}$ apart and both screened into the surface aquifer. The borehole measurements indicate that preferential flow is most likely to be occurring in the sandy layer at intermediate depth, because boreholes screened into this layer demonstrated much greater pore fluid conductivity variation. Standard deviations of the conductivities of boreholes screened into the sandy or tailing material were GW3 $=10.5 \mathrm{mS} / \mathrm{m}, \mathrm{GW} 5=6.6$ $\mathrm{mS} / \mathrm{m}$, and MW03 $=6.6 \mathrm{mS} / \mathrm{m}$; while standard deviations were much smaller for the boreholes screened into the surface layer, MW04 $=3.6 \mathrm{mS} / \mathrm{m}$, CGW1 $=3.6 \mathrm{mS} / \mathrm{m}$; and into the deeper bedrock well MW02 $=3.2 \mathrm{mS} / \mathrm{cm}$.

Two of the most variable wells, GW3 and GW5, show trends of decreasing fluid conductivity in the early field season (Figure 5). GW3 displayed a consistent decrease in fluid conductivity throughout the field season, starting at 42 $\mathrm{mS} / \mathrm{m}$ and ending near $18 \mathrm{mS} / \mathrm{m}$. GW5 decreased initially, from $89 \mathrm{mS} / \mathrm{m}$ to $73 \mathrm{mS} / \mathrm{m}$, before rising in late September and October back up to $84 \mathrm{mS} / \mathrm{m}$. No other wells showed consistent trends in fluid conductivity, though conductivity in MW03 did increase slightly over the study period.

Petrophysical relationships allow for examination of the feasibility that the observed pore fluid conductivity change could produce the development of the resistive anomalies at depth. Archie's Law relates pore fluid conductivity to bulk conductivity (Archie, 1942; Yuval \& Oldenburg, 1996):

$$
\sigma_{w}=\frac{\sigma}{a \theta^{m}}
$$

where

$\sigma_{w} \quad$ pore fluid conductivity $\mathrm{mS} / \mathrm{m}$

$\sigma$ bulk conductivity $\mathrm{mS} / \mathrm{m}$ 


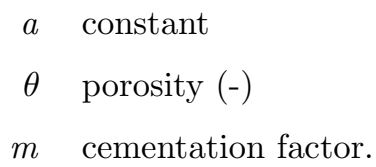

1 Equation 4 was used to calculate the pore fluid conductivity change necessary to 2 produce the observed bulk conductivity decreases of $15 \%$. This analysis is limited in that it assumes a consistent relationship between bulk conductivity and pore fluid conductivity (Day-Lewis et al., 2005), which, due to heterogeneities in the aquifer and in the resolution of the inversion, can be difficult to quantify precisely (Singha \& Gorelick, 2006). However, for the purposes of examining feasibility and possible ranges, standard parameter values from the literature suffice. Parameters were $\mathrm{a}=1.2, \theta=0.3$ and $\mathrm{m}=2$, all values consistent with clay-free unconsolidated rock reported in AMD literature (Yuval \& Oldenburg, 1996). Note that this calculation would not hold in the very near surface, where starting conductivities are drastically higher and where there are abundant clays with variable surface charge. The results of the calculation depend on initial conductivity, but near the center of the anomalies, where starting bulk conductivity is approximately $7.7 \mathrm{mS} / \mathrm{m}$, a decrease in pore fluid conductivity of about $10.6 \mathrm{mS} / \mathrm{m}$ would be required to produce a $15 \%$ decrease in bulk conductivity. This value is consistent with the range of observed decreases in conductivities in the wetland (up to a decrease of $16 \mathrm{mS} / \mathrm{m}$ pore fluid conductivity at GW5); therefore, TDS flushing likely explains the development of resistive anomalies at depth.

4.3. Flow conditions

The proposed mechanism of flushing TDS from preferential flow paths in the wetland to create localized resistive anomalies indicates that the initial July 12th baseline ER dataset captured the spring pulse of contamination, which is consistent with other measurements of spring flush timing. Time-lapse chemistry data show that mine outflow concentrations are highest roughly coincident 


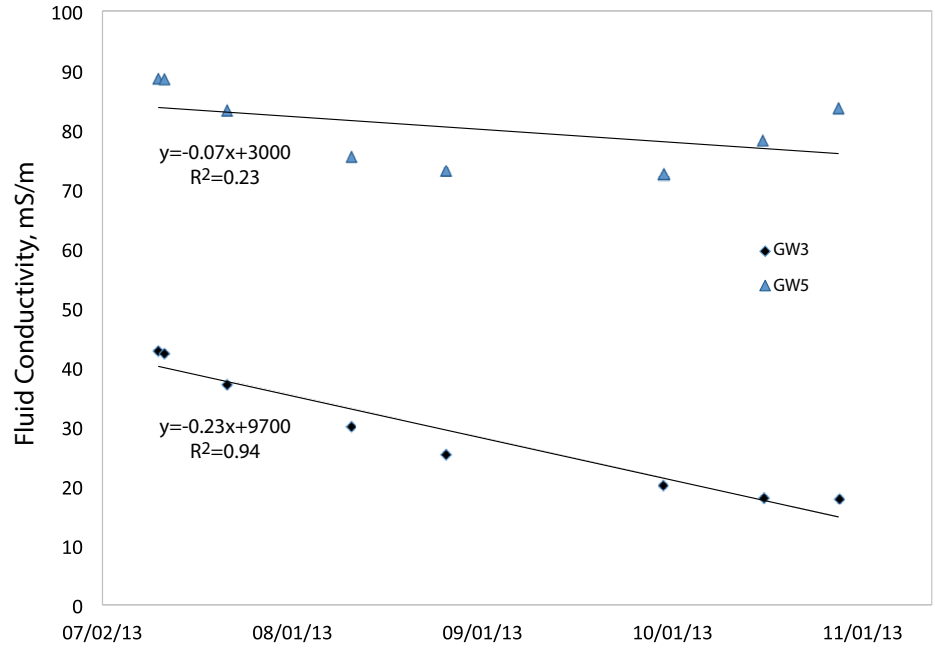

Figure 5: Pore fluid conductivity measurement trends over time collected in the site boreholes. 
1 with peak Snake River flow (Chapin \& Todd, 2012), which annually occurs in early summer (Figure 6). Unlike some other mines, concentrations from the Pennsylvania Mine do not show a traditional first-flush, but instead rise quickly to roughly 2-4 times their winter low values, before slowly dropping back down to baseline over the next several months (Chapin \& Todd, 2012). A similar trend was observed in the pore fluid conductivity measured in a monitoring well GW3, adjacent to the mine outflow (Figure 5).

The travel time from the mine to the wetland is complicated by seasonal variability in groundwater head gradients, but tracer studies have shown the travel time to be approximately 100 days during winter low flow (Mark Rudolph, personal communication). Because groundwater head gradients would be expected to be lower during winter and therefore produce slower flow, 100 days can be taken to be a maximum travel time. Therefore the pulse of contamination would be expected to reach the wetland sometime between peak flow in early June and 100 days later in early September, with a more likely arrival time in July or August, consistent with our background and early time-lapse measurements. The contrasting magnitudes and trends in the site borehole measurements indicate that movement of mining impacted water through the site is heterogeneous, and that arrival times are likely to be variable across the site (Figure 5).

The local flow maximum in mid-September of 2013 is the result of a storm ${ }_{21}$ in the middle of the study period. Storm events of this magnitude $(>1-2 \mathrm{~cm}$ 22 precipitation) have been demonstrated to cause concentration increases in the 23 Pennsylvania Mine outflow (Chapin \& Todd, 2012). This would be expected 24 to present a secondary pulse, observable in our data as a conductivity increase 25 and subsequent decrease. Pore fluid conductivity did increase in borehole GW5, 26 about $100 \mathrm{~m}$ upgradient of the ER array. It is proposed that this pulse had not 27 yet reached the ER array by the end of the survey. An arrival time of mid28 November to late January would be consistent with the travel times discussed 29 in the preceding paragraph, but no geophysical measurements were collected so during this time due to road conditions being impassable in the winter. 


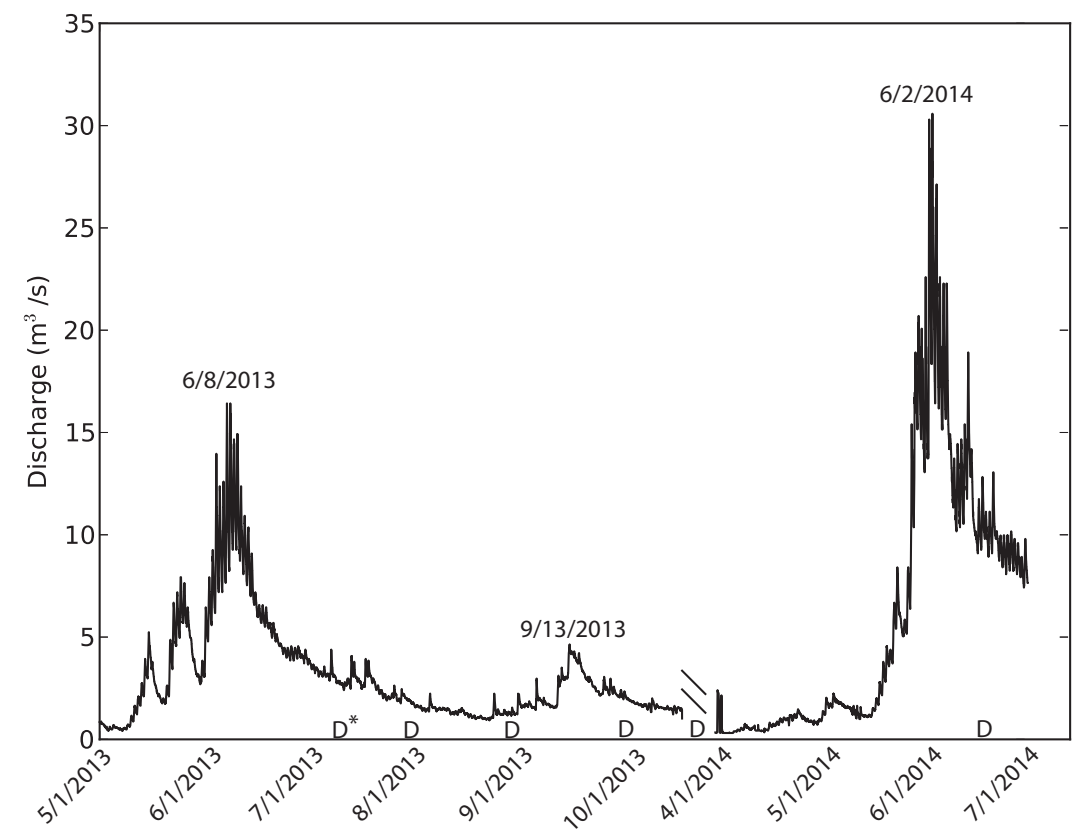

Figure 6: Snake River hydrograph. ER background (D*) and time-lapse (D) collection dates are shown. 


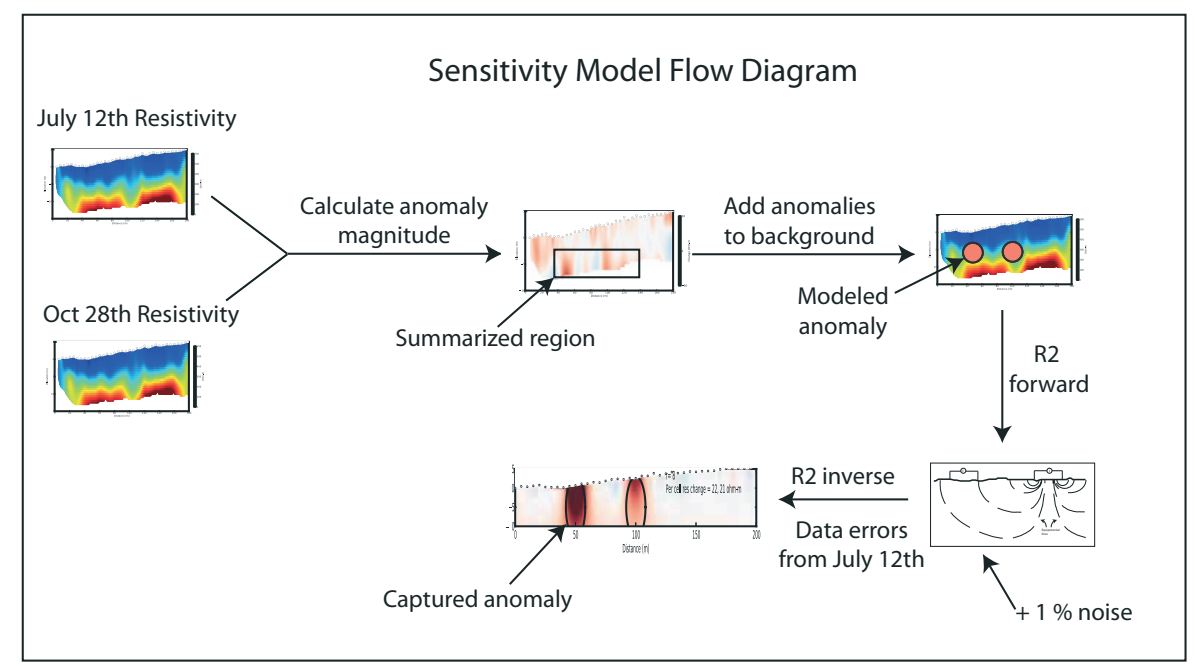

Figure 7: Flow diagram of the sensitivity modeling process.

\section{Sensitivity Analysis}

As a result of the non-uniqueness of the inverse problem, a large number of potential solutions exist that fit the data sufficiently well. The sensitivity of the inversion to changes in the ER model was investigated with synthetic data to develop an understanding of how regularization impacts the inversion's ability to resolve features of different sizes and contrasts, and to constrain the range of possible features that would be expected to produce the tomograms in Figure 4. Synthetic data parameters were chosen to mimic the electrical properties of this study, such that the results inform on real-world, non-uniform settings and geometries. The below process (schematically depicted in Figure 7) was followed:

1. Total resistivity change was calculated in a region encompassing the two anomalies at depth that developed between the background and final datasets, respectively collected on July 12 th and Oct 28th.

2. The recovered resistivity was then split into two anomalies and added onto the background resistivity model in locations that replicated the observed 
anomalies. The anomalies were emplaced at $\mathrm{y}=-5 \mathrm{~m}$ with circular geometries that had variable radii. Total mass remained constant and equal to the original anomaly mass, such that an anomaly larger in area would have lower contrast against the background.

3. A forward solution was computed for the synthetic anomalies using the same quadripole sequence that was used to collect field data.

4. The resulting forward model data were given $1 \%$ random noise to replicate the noise of field data. The same error parameters that were used to evaluate the field data were assigned to the forward model data.

5. The inverse solution was then computed in R2 (Figure 8).

In short, a forward and inverse solution was computed for the observed anomalies to test the inversion's ability to resolve anomalies of different sizes and contrasts. As was expected, results show that the model is more sensitive to larger anomaly structures (Figure 8). The inversion was unable to detect anomalies with radii of 0.5 to $1 \mathrm{~m}$ at relatively shallow depths of $5 \mathrm{~m}$, even though the contrasts of these anomalies are much larger. The analysis also shows that the left anomaly more easily resolved than the right anomaly, likely because of the greater average depth of the right anomaly. It is important to note that the inversions of the field data had different error fitting parameters, making a quantitative comparison to the inversions of the field data difficult.

\section{Discussion \& Conclusions}

Application of time-lapse ER allowed for non-invasive location and characterization of the resistive anomalies in an AMD-impacted wetland. Corroborating borehole measurements indicate that the resistive anomalies developed in response to localized decreases in pore fluid salinity, which are hypothesized to be driven by flushing of mining contamination through preferential flow paths in the wetland. The timing of the observed anomalies agrees well with the production of the seasonal first-flush and associated travel times. Because of smoothing inherent in inversions, the exact geometry of the flow paths is unknown, but the 


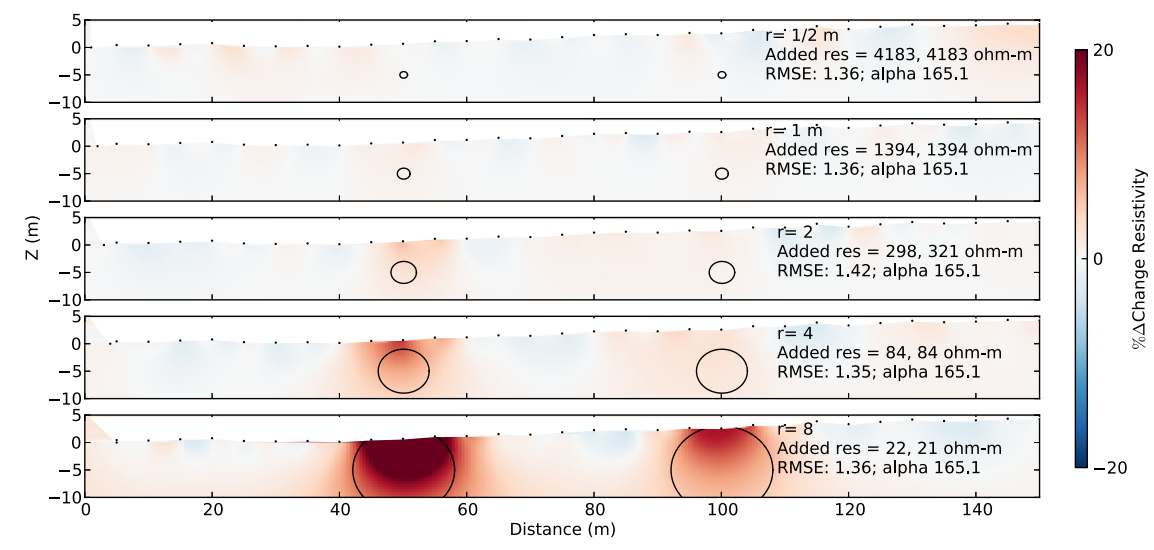

Figure 8: Cross sections of sensitivity modeling results for anomalies of different radii, denoted ' $r$ ' on each subfigure, units in meters. Also shown are the anomaly contrasts and inversion fitting results.

sensitivity tests reveal that they must be at least several meters in diameter.

Petrophysical relationships suggest that the localized changes in pore fluid con-

ductivity within the flow paths are on the order of hundreds of $\mu \mathrm{g} / \mathrm{L}$, which is

within the temporal variability of the conductivities in the boreholes as well as of the mine outflow (Chapin \& Todd, 2012).

The results of this study indicate that contamination may be discharging from the wetland to Peru Creek that would have been missed by spatially localized borehole sampling. Furthermore, this study shows that the wetland metals contributions would be expected to change over time as the pulse of contamination travels through the wetland. If the pore fluid changes are driven by leakage from the mine workings, there may be substantially more flow leaking from the mine workings than previously thought, which would have substantial implications for the hydrogeology of the mine workings and proposed remediation efforts.

Reactive transport models are an important tool for developing quantitative 16 predictions of remediation activities (for AMD examples, see Walton-Day et al., 17 2012; Benner et al., 2002); however, collecting sufficient data in the field to pa- 
rameterize these models in AMD-impacted regions can be difficult, especially considering that heterogeneous distributions of either potentially contaminantretarding agents or hydraulic conductivity can dramatically complicate interpretation of contaminant breakthrough curves (Malmström et al., 2008). In particular, preferential flow can cause separation of downstream breakthrough concentration peaks that mimic the effects of heterogeneous geochemical conditions in reactive transport (Malmström et al., 2008). Not differentiating the between the two conditions could lead to overestimates of the total amount of attenuation taking place (Malmström et al., 2008). Therefore, by offering preliminary contaminant pathway identification and characterization, the type of time-lapse geophysical data collected here may provide a valuable parameterization tool for reactive transport models, especially at sites with limited subsurface data.

14

\section{Acknowledgments}

This study was funded in part by NSF Grant EAR-0747629. Site access was permitted by the U.S. Forest Service, in particular through Paul Semmer and Brian Lloyd. Dr. Rob Runkel's time was supported through the USGS Toxic Substances Hydrology Program. Dr. Alexis Navarre-Sitchler provided helpful guidance throughout the project. Many people put in long hours in the field to make this work possible. In particular, CSM graduate students Ben Bader, Skuyler Herzog, Emmanuel Padilla, and Michael Sanders were of tremendous assistance. The authors would also like to thank Dr David Benson, Dr. Katie Walton-Day, Dr. Stan Church, Mark Rudolph, and Jeff Graves for their guidance. Any use of trade names is for descriptive purposes only and does not imply endorsement by the U.S. Government.

\section{References}

Alpers, C. N., Nordstrom, D. K., Verosub, K. L., \& Helm-Clark, C. (2007). Paleomegnetic Determination of Pre-Mining Metal Flux Rates at the Iron 
Mountain Superfund Site, Northern California. Eos, Trans. AGU, 88, Suppl.

2 Archie, G. E. (1942). The electrical resistivity log as an aid in determining some

3 reservoir characteristics. Transactions of the American Institute of Mining,

$4 \quad$ Metallurgical, and Petroleum Engineers, 146, 54-62.

5 Benner, S., Blowes, D., Ptacek, C., \& Mayer, K. (2002). Rates of sulfate reduc-

$6 \quad$ tion and metal sulfide precipitation in a permeable reactive barrier. Applied

$7 \quad$ Geochemistry, 17, 301-320.

8 Binley, A. M., \& Kemna, A. (2005). DC resistivity and induced polarization

9 methods. In Y. Rubin, \& S. Hubbard (Eds.), Hydrogeophysics (pp. 129-156).

$10 \quad$ N.Y.: Springer.

Bird, D. A. (2003). Characterization of anthropogenic and natural sources of acid rock drainage at the Cinnamon Gulch abandoned mine land inventory site, Summit County, Colorado. Environmental Geology, 44, 919-932.

Brusseau, M. (1994). TRANSPORT OF REACTIVE CONTAMINANTS MEDIA IN HETEROGENEOUS POROUS MEDIA. Reviews of Geophysics, (pp. 285-313).

Caine, J. S., \& Tomusiak, S. R. (2003). Brittle structures and their role in controlling porosity and permeability in a complex Precambrian crystallinerock aquifer system in the Colorado Rocky Mountain Front Range. Geological Society of America Bulletin, 115, 1410.

Chapin, T. P., \& Todd, A. S. (2012). MiniSipper: a new in situ water sampler for high-resolution, long-duration acid mine drainage monitoring. The Science of the Total Environment, 439, 343-53.

Crouch, C. M., McKnight, D. M., \& Todd, A. S. (2013). Quantifying sources of increasing zinc from acid rock drainage in an alpine catchment under a changing hydrologic regime. Hydrological Processes, 27, 721-733. 
1 Da Rosa, C. D., Lyon, J. S., Hocker, P. M., \& Udall, S. L. (1997). Golden dreams, poisoned streams: how reckless mining pollutes America's waters, and how we can stop it. Washington, DC: Mineral Policy Center.

Day-Lewis, F. D., Singha, K., \& Binley, A. M. (2005). Applying petrophysical models to radar travel time and electrical resistivity tomograms: Resolutiondependent limitations. Journal of Geophysical Research, 110, B08206.

Emerick, J., Huskie, W., \& Cooper, D. (1988). Treatment of discharge from a high elevation metal mine in the Colorado Rockies using an existing wetland. Proceedings from a conference at the annual meeting of the American Society for Surface Mining and Reclamation, (pp. 345-350).

Fey, D. L., Church, S. E., Unruh, D. M., \& Bove, D. J. (2001). U.S. Geological Survey Open-File Report 02-0330 Water and Sediment Study of the Snake River Watershed, Colorado. Technical Report.

Gélinas, P., Lefebvre, R., Choquette, M., \& Isabel, D. (1994). Monitoring and Modeling of Acid Mine Drainage from Waste Rock Dumps. Technical Report June Report GREGI 12.

Gray, N. F. (1996). Field assessment of acid mine drainage contamination in surface and ground water. Environmental Geology, 27, 358-361.

Kemna, A., Kulessa, B., \& Vereecken, H. (2002). Imaging and characterisation of subsurface solute transport using electrical resistivity tomography (ERT) and equivalent transport models. Journal of Hydrology, 267, 125-146.

LaBrecque, D. J., Miletto, M., Daily, W., Ramirez, A., \& Owen, E. (1996). The effects of noise on Occams inversion of resistivity tomography data. Geophysics, 61, 538-548.

Loke, M. H., Chambers, J. E., Rucker, D. F., Kuras, O., \& Wilkinson, P. B. (2013). Recent developments in the direct-current geoelectrical imaging method. Journal of Applied Geophysics, 95, 135-156. 
Lovering, T. (1935). Geology and ore deposits of the Montezuma Quadrangle,

2 Colorado. Technical Report Professional Paper 178 Geological Survey.

3 Malmström, M. E., Berglund, S., \& Jarsjö, J. (2008). Combined effects of spa-

4 tially variable flow and mineralogy on the attenuation of acid mine drainage

$5 \quad$ in groundwater. Applied Geochemistry, 23, 1419-1436.

6 McKnight, D. M., \& Bencala, K. E. (1990). The Chemistry of Iron, Aluminum,

7 and Dissolved Organic Material in Three Acidic, Metal-Enriched, Mountain

$8 \quad$ Streams, as Controlled by Watershed and in-Stream Processes. Water Re-

$9 \quad$ sources Research, 26, 3087.

10 Merkel, R. H. (1972). The use of resistivity techniques to delineate acid mine

11 drainage in ground water. Groundwater, 10.

Miller, J. R., \& Miller, S. O. (2007). The water column-concentration and load. In Contaminated Rivers (pp. 103-126). Springer Netherlands.

Morin, K., \& Hutt, N. (1994). An empirical technique for predicting the chemistry of water seeping from mine-rock piles. In Proceedings of the Third International Conference on the Abatement of Acidic Drainage. Musgrave, H., \& Binley, A. (2011). Revealing the temporal dynamics of subsurface temperature in a wetland using time-lapse geophysics. Journal of Hydrology, 396, 258-266.

Nordstrom, D. K. (2009). Acid rock drainage and climate change. Journal of Geochemical Exploration, 100, 97-104.

Nordstrom, D. K. (2011a). Hydrogeochemical processes governing the origin, transport and fate of major and trace elements from mine wastes and mineralized rock to surface waters. Applied Geochemistry, 26, 1777-1791.

Nordstrom, D. K. (2011b). Mine Waters: Acidic to Circumneutral. Elements, 7, 393-398. 
Oldenburg, D. W., \& Li, Y. (1994). Inversion of induced polarization data.

$2 \quad$ Geophysics, 59, 1327-1341.

3 Oram, L. L., Strawn, D. G., Morra, M. J., \& Möller, G. (2010). Selenium

$4 \quad$ biogeochemical cycling and fluxes in the hyporheic zone of a mining-impacted

$5 \quad$ stream. Environmental Science \& Technology, 44, 4176-83.

6 Pollock, D., \& Cirpka, O. A. (2012). Fully coupled hydrogeophysical inver-

7 sion of a laboratory salt tracer experiment monitored by electrical resistivity

$8 \quad$ tomography. Water Resources Research, 48, W01505.

9 Rucker, D. F., Glaser, D. R., Osborne, T., \& Maehl, W. C. (2009). Electrical

10 Resistivity Characterization of a Reclaimed Gold Mine to Delineate Acid Rock

$11 \quad$ Drainage Pathways. Mine Water and the Environment, 28, 146-157.

Rudolph, M. (2010). Dye injection and sampling and analysis plan Cinnamon 
Spindler, K., \& Olyphant, G. (2004). Geophysical investigations at an aban-

2 doned mine site subjected to reclamation using a fixated scrubber sludge cap.

3 Environmental \& Engineering Geoscience, X, 243-251.

4 Sullivan, A. B., \& Drever, J. I. (2001). Spatiotemporal variability in stream 5 chemistry in a high-elevation catchment affected by mine drainage. Journal 6 of Hydrology, 252, 237-250.

7 Telford, W. M., \& Sheriff, R. E. (1990). Applied Geophysics volume 1. Cam$8 \quad$ bridge University Press.

9 Tiedeman, C. R., \& Hsieh, P. A. (2004). Evaluation of longitudinal disper10 sivity estimates from simulated forced- and natural-gradient tracer tests in ${ }_{11}$ heterogeneous aquifers. Water Resources Research, 40, 1-15.

12 Tikhonov, A., \& Arsenin, V. (1977). Solutions of ill-posed problems. teristics for the Snake River, North Fork of the Snake River, Peru Creek, and Deer Creek in Summit county, Colorado: 2001 to 2002. Technical Report University of Colorado, Institute of Arctic and Alpine Research.

Verplanck, P. L., Nordstrom, D. K., Bove, D. J., Plumlee, G. S., \& Runkel, R. L. (2009). Naturally acidic surface and ground waters draining porphyryrelated mineralized areas of the Southern Rocky Mountains, Colorado and New Mexico. Applied Geochemistry, 24, 255-267.

Walton-Day, K., Runkel, R. L., \& Kimball, B. A. (2012). Using Spatially Detailed Water-Quality Data and Solute-Transport Modeling to Support Total Maximum Daily Load Development. JAWRA Journal of the American Water Resources Association, 48, 949-969.

Ward, A. S., Gooseff, M. N., \& Singha, K. (2010). Characterizing hyporheic transport processes - Interpretation of electrical geophysical data in coupled stream-hyporheic zone systems during solute tracer studies. Advances in Water Resources, 33, 1320-1330. 
1 Wood, R. H. I., Bird, D. A., \& Sares, M. A. (2005). Mine site history and water-

2 shed characterization of the Cinnamon Gulch Area, Dillon Ranger District,

$3 \quad$ White River National Forest, Summit County, Colorado. Technical Report

$4 \quad$ Colorado Geological Survey, Department of Natural Resources.

5 Younger, P. L. (1997). The longevity of minewater pollution: a basis for decision-

6 making. The Science of the Total Environment, 194-195, 457-66.

7 Yuval, D., \& Oldenburg, W. (1996). DC resistivity and IP methods in acid mine

8 drainage problems: results from the Copper Cliff mine tailings impoundments.

$9 \quad$ Journal of Applied Geophysics, 34, 187-198.

Zhu, C., Anderson, G., \& Burden, D. (2002). Natural Attenuation Reactions at 11 a Uranium Mill Tailings Site, Western U.S.A. Groundwater, 40, 5-13. 